\title{
Teachers' Help of Students to Use English in Selected Secondary Schools at Nekemte, Ethiopia
}

\author{
Tamiru Olana $^{1 \star}$ and Italo Beriso ${ }^{2}$ \\ ${ }^{1}$ Department of Language Studies and Literature, Institute of Language Studies and Journalism, \\ Wollega University, Post Box No: 395, Nekemte, Ethiopia \\ ${ }^{2}$ Department of Foreign Languages and Literature, Institute of Language Studies, Addis Ababa University, \\ Addis Ababa, Ethiopia
}

\begin{tabular}{|c|c|}
\hline Abstract & Article Information \\
\hline \multirow{3}{*}{$\begin{array}{l}\text { The objective of this study was to explore subject area teachers' help of students to use the } \\
\text { Target Language (TL) in classrooms. For the investigation, a mixed-method research } \\
\text { approach was used under the umbrella of pragmatic paradigm of research design. Four } \\
\text { Grade Nine History and Geography teachers were purposively selected for the study from two } \\
\text { secondary schools in Nekemte town. The data were collected through interview and } \\
\text { classroom observations. The data from the interview and the lesson transcripts were } \\
\text { analysed by using content analysis of the transcripts. The results indicated that teachers } \\
\text { played the dominant role in using students' mother tongue and the TL. The data from the } \\
\text { lesson transcripts showed that History teachers and Geography teachers hardly showed } \\
\text { efforts to promote students' use of the TL. From the findings, it was concluded that subject } \\
\text { area teachers need to be aware of the additional responsibilities of promoting students' } \\
\text { language skills and thus work in collaboration with English teachers in this regard. }\end{array}$} & $\begin{array}{l}\text { Article History: } \\
\text { Received : } 25-09-2014 \\
\text { Revised }: 10-12-2014 \\
\text { Accepted }: 16-12-2014\end{array}$ \\
\hline & $\begin{array}{l}\text { Keywords: } \\
\text { Code switching } \\
\text { Medium of instruction, } \\
\text { Mother tongue } \\
\text { Target language } \\
\end{array}$ \\
\hline & $\begin{array}{l}\text { *Corresponding Author: } \\
\text { Tamiru Olana } \\
\text { E-mail: } \\
\text { olana.tamiru@yahoo.com }\end{array}$ \\
\hline
\end{tabular}

\section{INTRODUCTION}

English is used for many purposes around the world than ever before. For example, internet and related information technologies, among other things, are greatly becoming influential in increasing the demand for English worldwide (Crystal, 1997). Likewise, English has multipurpose roles in Ethiopia. It is the only language which can keep us in touch with the rest of the world. That is why the document of the Ministry of Education (Mol, 2007) reveals that English is a corner stone in the development of Ethiopia's education, communication system, technology and commerce.

To this effect, endeavors have been carried out to boost up the status of English in general and to intensify the English proficiency of teachers and students in particular. That is why it is taught as a subject at all levels being given the highest number of periods, at an average of one period a day, Monday through Friday, while other subjects (Social Studies and Sciences, for example,) are comparatively given a maximum of three periods a week (Awol, 1999). English is focused because of the role it plays as the Mol starting from secondary level of education and a determining factor it has on secondary school students to join higher institutions. However, the improvement of teachers' use of the TL and help of their students to use the language in subject area classes is still under question. Thus, the aim of this study was to explore the extent to which History teachers, and Geography teachers use English as role models \& help students improve their TL oral practices.
Most teachers in Ethiopian high schools are not proficient enough in English, which, as a result, is the cause for the great majority of students' lack of the basic language skills. This in turn has an adverse effect on the students' performance. Williams (1984) in Tadese (1990) stresses that some of the overseas students fail to survive academically because of language difficulties. This situation forces teachers to translate everything into Amharic or other vernaculars in their efforts to make students understand what they learn (Seime, 1989).

The researcher could informally observe that many secondary school teachers are not concerned with their students' use of the TL as such nor do they try to be models for their students in using it. Rather, they very frequently, adhere to code-switching maybe for fear that the students cannot understand the subjects they learn if explained in the TL. This attempt of many teachers is believed to reduce the students' opportunity to develop their TL oral competence (Allwright and Bailey, 1991).

It is true that teachers of English play a leading role in providing learners with the knowledge, skills and understanding they need to read, write, speak and listen effectively (Uys et al., 2007). However, their subject area teachers limitedly assist them to do so (Crandall, 1998). Similarly, Ethiopian secondary schools subject area teachers do not seem helpful to their students in two ways. One is that they may take more of the class time and give their students little or no time to practice the TL. 
The other is that they themselves might be incompetent to use the TL.

As far as the researcher's knowledge goes, there is no local research conducted at secondary school level to investigate the efforts made by subject area teachers to improve students' use of the TL. The researcher also feels that the problem prevails in Nekemte town secondary schools drawing on his informal experiential knowledge he developed as a teacher in the town for several years. Therefore, it is important to investigate the extent to which subject area teachers help students use the TL in subject area classrooms and the ways Geography teachers and History teachers help their students use the target language to improve their oral interaction.

\section{Need of Subject Area Teachers' Help to Improve Students' TL Use}

Teachers can help students practice the TL, other than in English-as-a-subject classrooms, in many opportunities. As Stubbs (1992) puts it, "Every teacher is an English teacher". Richards and Rodgers (2001) also emphasise that language skills should be taught by subject area teachers; not left exclusively for the English teacher.

Vollmer (2006) further explains that academic language skills and competences in different nonlinguistic subjects should systematically be developed in close connection with the content, which requires language awareness, language education attitude, and language skills on the part of each subject teacher. Clegg (2002) contends that although language specialists play a key role in L2-medium schools, language-sensitive developments in schools are largely unsuccessful if left only to language teachers. More specifically, as students have little opportunity for exposure to the TL outside the classroom and teachers are normally the only expert users of the TL, teachers should maximise the TL use. Chaudron (1988) extends this idea saying that teachers should provide their students with a rich TL environment by using the TL not only for academic content instruction but also for disciplinary and managerial matters as well.

The need of the subject area teachers to enhance students' language proficiency is not to levy the burden of language teaching such as sentence structures, grammar and composition skills on them by overtaking the work of English teachers. In this regard, the researcher is fully aware that the main objective of subject area teachers is to teach contents of their respective subjects as it should be. However, it is to claim that the opportunities provided in the language classes are just not enough to develop proficiency in all the skills of English which students need for academic growth in the content areas. At the same time, it is to indicate that students need all the possible support they can get from the subject area teachers to practice the TL skills. For example, to develop the vocabulary required for academic work and to provide background information that will fire students' imagination and creativity, subject area teachers should play role (Ortner, 2003).
When looking at classroom interaction using the TL, according to some studies, the combination of content and language is not always that much successful mainly because subject area teachers are generally not aware of the use of it. In a study in a Dutch secondary school, for instance, it was found out that teachers focused on the content to be taught to such an extent that they paid little attention to students' language, and their share in the interaction (Snow, 1998). This is generally not so because teachers would not want to offer languagesensitive content instruction; rather it may be because they have not been made aware of how to do it' (ibid.).

Another study that was conducted by Musumeci (1996) describes typical classroom interaction as dominated by teachers who ask display questions, receive reference questions from students, and modify their speech when they get signals of non-understanding without giving a chance to students to speak. Musumeci also reported that in interviews and questionnaires, teachers and students evaluated their classroom interaction as appropriate classroom behaviour, linked to the teachers' time management (ibid.). The two studies imply that subject area teachers need to be aware of the importance and management of language in content area classes.

In order to manage their teaching, thus, teachers should have language competence to a greater degree than that is expected of their learners (Thomas, 1987). Especially, in contexts where English is widely used as the Mol, teachers should be trained to use their language resources effectively. Richards and Nunan (1990) also report that a course that focuses on the effective use of the TL should be an important part of the training of any teacher; especially, it is crucial where a second language is the Mol since the vital connection is at risk.

\section{MATERIALS AND METHODS}

\section{The Research Approach}

Research that aims at exploring processes involving a phenomenon such as classroom research may find the combination of quantitative and qualitative methods more amenable. The two methods do not belong to separate research paradigms and, thus, can sensibly be used within the same investigation (Scott and Usher, 2011). The compelling reason for implementing the mixedmethods approach in this research was, thus, to expand the understanding of the issue by painting a relatively more complete picture of the situation by looking into its different aspects, i.e., the existing behaviours with regard to teachers help of students.

\section{Selection of the Research Site}

The study was conducted in Nekemte town, the capital of East Wollega Zone, Oromia Regional State. Two high schools in the town were selected purposively for two reasons. The first reason was that when the researcher worked as a teacher at one of the high schools, he informally observed many teachers extensively using Oromo instead of English let alone helping their students uses the TL. The second reason was the proximity of the schools to the researcher's work place (Wollega University). This could give the researcher both administrative convenience and good insight into the actual research concern. 


\section{Selection of Teachers}

The teacher participants were selected from two secondary schools. The researcher was informed that the two schools follow the same procedure in assigning teachers to their respective classes. For example, if Mr. $X$ is a Geography teacher, he might be assigned to either Grade 9 or Grade 10 or to both, which minimised the chance of getting a teacher who teaches only the class under research (Grade 9). Accordingly, the researcher asked the directors if there are teachers who teach History and Geography only at Grade 9. Fortunately, from each school, there were one Geography teacher and one History teacher who solely teach the required grade. Therefore, it did not demand the researcher to search for other techniques to select the four teachers from other teachers. Underneath, the profile of the selected teachers is presented.

Table 1: Bio-data of the selected geography teachers and history teachers

\begin{tabular}{|c|c|c|c|c|c|c|c|}
\hline \multirow{2}{*}{ No. } & \multirow{2}{*}{ Work Place } & \multirow{2}{*}{$\begin{array}{l}\text { Teacher's } \\
\text { Code }\end{array}$} & \multirow{2}{*}{$\begin{array}{l}\text { Graduated } \\
\text { From }\end{array}$} & \multicolumn{2}{|c|}{ Qualification } & \multirow{2}{*}{$\begin{array}{c}\text { Subject He/She } \\
\text { Teaches }\end{array}$} & \multirow{2}{*}{$\begin{array}{c}\text { Service } \\
\text { Year }\end{array}$} \\
\hline & & & & Major & Minor & & \\
\hline 1 & Biftu Nekemte & $\mathrm{T} 1$ & Jimma University & Geog. & History & Geog. & 8 \\
\hline 2 & Secondary School & $\mathrm{T} 2$ & N.G.U.C & History & Geog. & History & 30 \\
\hline 3 & Derge & T3 & Jimma University & Geog. & History & Geog. & 8 \\
\hline 4 & Secondary School & $\mathrm{T} 4$ & Jimma University & History & Geog. & History & 25 \\
\hline
\end{tabular}

The table above indicates that teachers of both subjects are well experienced in teaching their respective subjects. Though the geography teachers have a few years' teaching experience as compared with that of the History teachers, they have the same years of teaching experience. All of the teachers teach the subjects in which they were qualified. All the teachers but one, who graduated from New Generation University College, graduated from Jimma University.

Grade Nine was chosen because it is where the subjects make a shift of Mol from MT to English. Therefore, it is believed that studying teachers' help of students to use English during classroom interaction is at this initial stage so that, if there are problems regarding the use of the TL, some remedy will be thought for before it obstructs the students' preparatory and tertiary level education in the future.

\section{Instruments}

\section{Classroom Observation}

Scholars of the field divide observation into two: participant observation and non-participant observation. In this study, taking the position of non-participant observer, the researcher observed four teachers' classes (a History teacher's and a Geography teacher's classes from each high school).

To collect the necessary data through classroom observations, the researcher used audio recording procedures. One particular advantage of this approach is that it is useful to the extent that it is possible to focus on a single issue for one viewing, such as teacher talk, and then replay the tape to focus on a different issue.

Twenty lessons (10 History and 10 Geography lessons) were observed. However, two observations of each teacher's classes were not recorded because they were used to familiarise the researcher with the participants so that alteration of behaviour might be minimised during the three recording sessions. Therefore, from the twenty observations, twelve of them were audiorecorded. It was hoped that from the twelve-recorded lessons, ample information could be collected to show how the teachers help students use the TL.

\section{Teachers' Interview}

Interview permits in-depth information gathering, free response and flexibility that cannot be obtained by other procedures (Seliger and Shohamy, 1989). Furthermore, data that have not been foreseen through other procedures can be probed and obtained through interviews.

In this research, semi-structured interview was used because it does not adhere merely to statistical and closed questions, which inhibit getting ample information; neither does it allow a much-uncontrolled kind of conversation. Accordingly, an interview guide, which has 4 open-ended but semi-structured items, was designed for the four interviewees.

The next step was to get a convenient place to conduct the interview. Accordingly, the researcher asked the school administrators to provide him with a convenient place to conduct the interview. The administrators permitted the researcher to use the Social Sciences Department and told the school guards to keep the environment silent until the interview was over. As a result, the interview could be conducted in the departments of the two schools without any disturbance.

\section{Methods of Data Analysis}

The teachers' interview and the lesson transcripts were analysed both quantitatively and qualitatively to investigate the extent of teachers' use of the TL and identify the ways subject area teachers help students use the TL.

\section{Ethical Considerations}

To be cautions of the ethical considerations, first, the researcher requested a permission letter from the Institute of Language Studies and Journalism (WU). Then, he took the letter to the two schools. As soon as the researcher reached the schools, he informed the directors of the schools that he wants to conduct research in the schools particularly with Grade 9 Geography teachers and History teachers. Showing their agreement, the directors immediately introduced the investigator to the targeted teachers so that they could co-operate. The teachers also showed their willingness. The researcher informed the participants that participation in the study is voluntary and 
Tamiru Olana and Italo Beriso

completely anonymous and that the retrieved information would be used only in this study.

\section{RESULTS AND DISCUSSION}

\section{The Extent of Teachers' Use of the Target Language}

Six Geography lessons and six History lessons were recorded for 432 minutes. Indeed, the conventional class time in Ethiopian secondary schools context is 40 minutes, which could have taken the researcher 480 minutes to record the 12 lessons.

However, 14 minutes in the Geography classes were not recorded because 9 and 5 minutes respectively were wasted as the classes began late and the teachers left the classes early. Similarly, 34 minutes in the History classes

\section{Sci. Technol. Arts Res. J., Oct-Dec 2014, 3(4): 179-186}

were not included for the reason that (1) the teachers wasted 10 minutes because they entered late and left the class 5 minutes earlier than the normal class time and (2) the students and the teachers kept silent for 19 minutes at different times. Totally, 48 minutes were not included in the conventional class time of the twelve lessons because the teachers and the students did not use them for oral interaction. Thus, the subjects effectively used 432 minutes as the class time.

The focus of this research was not to investigate the amount of class time students used. However, because both teachers and students share the same class and the same time, it is evident to use the data which hold the extent to which both parties use the class time

Table 2: Summary of the number of words spoken by students and teachers

\begin{tabular}{ccccccccc}
\hline \multirow{2}{*}{ Subjects } & \multicolumn{2}{c}{ English } & \multicolumn{2}{c}{ Oromo } & \multicolumn{2}{c}{ Amharic } & \multicolumn{2}{c}{ Total } \\
\cline { 2 - 9 } & Words & $\%$ & Words & $\%$ & Words & $\%$ & Words & $\%$ \\
\hline SS & 1406 & 3.6 & 1775 & 4.5 & 185 & 0.4 & 3366 & 8.5 \\
TS & 24480 & 62.2 & 10454 & 27.6 & 637 & 1.7 & 35571 & 91.5 \\
\hline Total & $\mathbf{2 5 8 8 6}$ & $\mathbf{6 5 . 8}$ & $\mathbf{1 2 2 2 9}$ & $\mathbf{3 2 . 1}$ & $\mathbf{8 2 2}$ & $\mathbf{2 . 1}$ & $\mathbf{3 8 9 3 7}$ & $\mathbf{1 0 0}$ \\
\hline \multicolumn{4}{c}{ SS $=$ Students in the Four Teachers' Classes; TS= The Four Teachers }
\end{tabular}

Table 2 above shows that there were totally 38937 words spoken by the subjects during the twelve lessons class time. From the total words, there were 25886 English words spoken which cover $65.8 \%$ of the total class time. The data also indicate that there were 12229
Oromo words spoken by the subjects which hold $32.1 \%$ of the total class time. The data also show that there were 822 Amharic words spoken by the subjects, which is $2.1 \%$ of the total class time.

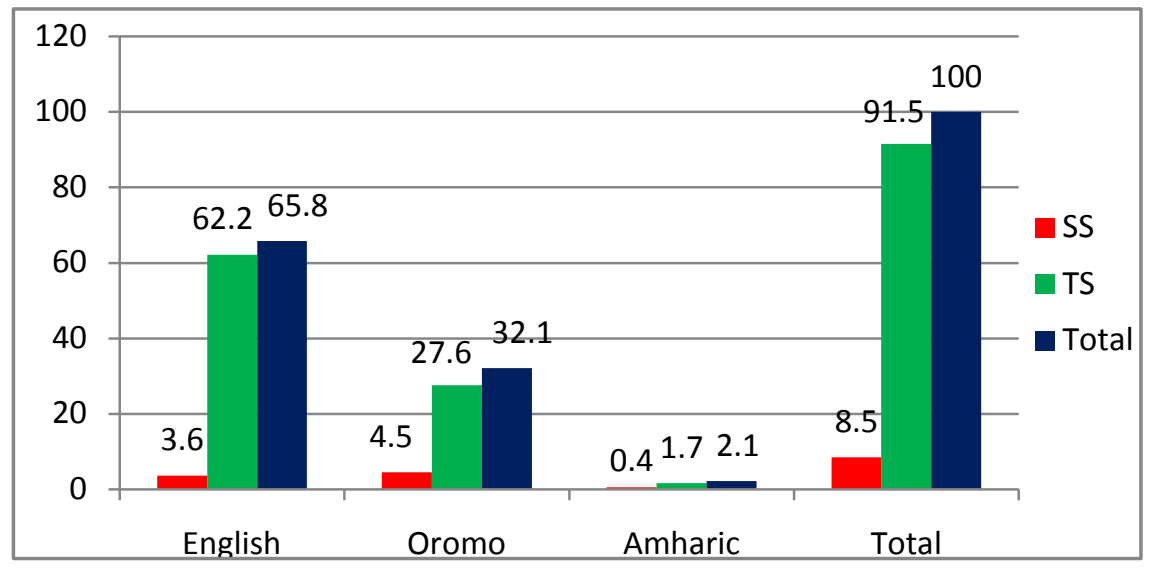

Figure 1: The number of words spoken in percentages per language by teachers and students

A study of teacher-student interaction research conducted by Musumeci (1996) in a secondary school, in which content-based instruction was being conducted, has indicted that teacher talk time occupies about $66 \%$ to $72 \%$ of the class time. By comparing Musumeci's study result with the present one $(91.5 \%)$, one can comment that teachers in the targeted high schools over-utilize the class time, which implies that students could not get a chance to do different classroom activities, through which they might practice the TL.

Teachers' use of the TL to the amount indicated $(62.2 \%)$ in this study may not seem discouraging when one sees on the surface. However, if critically seen, teachers could use this amount because they did not give students a chance to use it. Neither did they give students a chance to speak in local languages as the data clearly indicate that from the $34.3 \%$ class time the subjects spoke in the local languages, the teachers' share was $29.3 \%$ while that of the students was only $4.9 \%$ of it. This implies that whether it is in the TL or in the local languages, teachers dominantly use the class time contrary to the current student-centered approach, which is believed to enable students learn by themselves with teacher as a facilitator.

Wolfaardt's (2005) study has a close relation with the present study because it deals with the amount of EMI to be used in schools. He suggests that for secondary schools (Grades 8-10), in the Ethiopian case (Grades 9$10)$, using EMI $80 \%$ of the class time is appropriate. However, the result of the present study $(65.8 \%)$ shows that students and teachers of the targeted schools lag behind what Wolfaardt estimated in his study. This implies that there is a great discrepancy between what the subjects estimated they use and their actual performance. 


\section{Tamiru Olana and Italo Beriso}

Therefore, it could be suggested that if students and teachers in the targeted high schools use the class time combining local languages and the TL, as indicated above, there is a fear that the attempt of using English as the Mol will totally diminish and leave its place for the local languages.

\section{Teachers' Responses Related to the help they Provide Students}

Although language specialists play a vital role in L2medium schools, language-sensitive developments in schools are largely unsuccessful if they are left only to language teachers (Clegg, 2002). More specifically, as students have little opportunity for exposure to the TL outside the classroom and teachers are normally the only expert users of the TL, teachers should maximise the TL use in class in order to provide a rich environment to practice the TL (Chaudron, 1988). Therefore, it is worth investigating the efforts made by secondary school Geography teachers and History teachers to help students improve their use of the TL.

Attempts were made to get ample information from the four interviewees (T1, T2, T3 and T4) to investigate the ways they help students use the $T L$ in History and Geography classrooms. Accordingly, they were asked to explain whether they help their students improve their TL proficiency or not and the ways they help them. The data indicate that they theoretically help their students. For example, $\mathrm{T} 1$ reported the ways he tries to avoid excessive use of the MT in the following way:

Most of the time, the measure that they take to divert their idea to speak English for myself, I did not reply, I did not answer the questions of the students that made in Oromo language; I reply in English. Then, in turn, the student tries to answer in English.... If the student did not understand what I asked him in English, I repeat the question to Oromo and then turn back to English.

The above extract clearly indicates that when students ask questions in Oromo, the teacher repeats the students' question in English and then continues speaking in English. T3 and T4 also responded in a similar way. For example, T4 reiterated that he motivates the students to speak in the TL by speaking in English as a role model himself. See the next extract:

To motivate the students to speak in English, the only method I ... have in the classroom is accepting in whatever broken English they approach me. I simply accepting and motivating even if they speak in a very I mean in broken English language. One is I motivate their English method.

T3 also repeated what the two interviewees replied. However, the teachers were not observed paying attention to the use of the TL except T1 who tried to implement what he reported in the interview. The rest were observed using English, Oromo and Amharic excessively let alone motivating students to use the TL. Thus, what the subjects report they do, sometimes deviates from their actual classroom performances.

The interviewees were also required to tell whether they help their students by teaching the list of words given in the students' textbooks or not. They reported that though there is an attempt to consider teaching the key terms, they do not emphasise them due to time

\section{Sci. Technol. Arts Res. J., Oct-Dec 2014, 3(4): 179-186}

constraints. For example, T4 emphasised that he could not teach the key terms at all because of shortage of time to teach the subject matter as indicated in the next extract:

The key terms given at the beginning of each chapter are very important to help the students. Those key terms even I consider them as basic concepts in the chapter. Therefore, the great problem we have now to solve such English language problem is that we do not have time.

Traditionally, it is believed that subject area teachers should focus only on their subject matter and English teachers should focus on teaching English. The researcher wanted to know whether the subjects of this study have the same perception or not. T1 pointed out that it is not only the work of English teachers but also the work of Geography teachers. However, he reported that he could not use activities like debate, discussion, etc to help students interact in the classroom because of a lack of time.

Finally, the teachers were asked the ways students and teachers can improve their English proficiency. They provided constructive suggestions among which two of them are quoted below. T4 responded as follows:

One, the students must develop their skill of English language from the very beginning, from the elementary school. Secondly, even after coming to the high school, as to me easily communicate every minute in English even not only in the classroom but out of the classroom in the school campus of the school. Every student always uses English language they can simply improve their English language. I think this way. Additionally, continuous workshop should be given for the teachers to improve their language.

The extract indicates that the improvement has to start at elementary schools. Further, it reveals that if sustainable improvement is needed, students should be encouraged to practice the language not only in classrooms but also outside classrooms. Extending his speech, T4 recommended that teachers should be provided with continuous workshops on how to use English in classrooms. T2 added similar points as to how students can improve English language communication skills. T3 underlined that it would be beneficial if trainings such as ELIP do not terminate and if schools encourage teachers and students to speak the TL in the school environment (see the extract below):

ELIP (English Language Improvement Programme) is a very important programme. Really, it is a good programme. Most of us we came to speak a little bit English because of ELIP. It has to continue repeatedly. Another one the teachers themselves they have to try to speak let it be whatever it is. Let it be its grammatical articulation is not right. ... The school itself has to do something. He has to initiate our teachers to speak and communicate with this media in the compound.... In addition, our teachers must read English materials reading must be their habit so that we may overcome the problems, we may avoid in the end.

T3 further suggested that subject area teachers might help their students improve their use of the TL if they cooperate with English teachers though the English teachers should shoulder more responsibility. Conversely, he advises English teachers to play a great role even if 


\section{Tamiru Olana and Italo Beriso}

helping students improve their TL use is also expected from the subject area teachers.

The interview data indicate that teachers encourage students to use the TL by giving students' classwork and homework and let them report it in the TL as it improves their oral communication. To prove or disprove the responses, it was necessary analysing the lesson transcripts of the four teachers. Accordingly, the analysis of core examples is presented below:

\section{Analysis of Data from the Lesson Transcripts}

By common understanding, the use of code-switching in classrooms, if carefully used, is to help students understand the subject matter they learn. However, there are conditions in which teachers switch to students' MT in a way it can affect students' use of both languages. In this section, the help offered by History teachers and Geography teachers and the merits and demerits of these helps will be presented with some crucial examples cited from the lesson transcripts.

\section{Analysis of Data Related to Help from T1}

$\mathrm{T} 1$ tried to help students understand the subject matter he taught though some problems were detected (see the extract):

T1: What does it mean... what is the meaning of this term? The ten-degree isothermic line in the southern region or the southern boundary of tundra region when we say like that what does it mean that? Yee, maal jechuudha? Yeroo ten degree isothermic [laayiniin baawundarii tunduraa riijiniiti] jennu, maal jechuudha? (Yes, what does it mean? What do we mean when we say ten-degree isothermic line is at the boundary of tundra region?). That means the southern end. That means we said tundra is found only in the northern,

\section{S: Hemisphere.}

If we consider the way the teacher translated the words, [laayinii]n (line), baawundarii (boundary), [riijinii]ti (region), he directly used the stem of English words and added some morphemes to the words, which may not show that he shifted language and helped students. Rather, it is believed that such kind of shifting without changing the entire stem of the target word might create a serious problem on students' pronunciation of the $T L$ for they pronounce it the way they experienced in the MT (Oromo).

One strong side of T1, however, was that he discussed some concepts in a way that students could show their participation. He asked them to identify the difference between omnivorous and carnivorous animals as in the next extract:

T1: So, discuss please, discuss and clearly identify how dog can be classified; whether it can be classified under omnivorous or carnivorous clearly. Meemee irra deebi'aatii akka sareen [omniivorasii] sirrii yookiinimmoo [karniivorasiitti] dabalamuu ishee adda baasuudhaaf mee wal walitti himaa (Translated to Oromo by T1). Please tell to each other (a sample group was focused to be recorded).

\section{S: Dog eating all injera, meat and bread.}

Though the teacher tried to make the concept clear, he did not translate the key terms omnivorous and
Sci. Technol. Arts Res. J., Oct-Dec 2014, 3(4): 179-186

carnivorous, which are believed to hinder students from understanding what he was saying. The researcher could come to this conclusion as he was observing a group of students who were sitting close to him and saying in murmur, 'Maal jechuudhaa omniivorasiifi karniivorasiin mataan isaa?" (What is the meaning of omnivorous and carnivorous itself)? Therefore, it might be concluded that the teacher could not help majority of the students understand the subject matter he taught by giving clear meaning of the terms, which might contribute to their knowledge of vocabulary. Furthermore, even though the teacher gave classwork for discussion, he did not focus on the students' TL practice.

\section{Analysis of Data Related to Help from T2}

The data from T2's lesson transcripts indicate that he did not make much effort to help students use the TL. In the next extract, the way he tried to motivate students to show their participation does not indicate the use of the TL.

T2: Barreessuu dhiisiitii warra kaanii wajjin yaada kee wal qabsiifadhu (Stop writing and discuss your ideas with others.) Extend your ideas clearly, don't afraid. Ok [giruuppii] kana keessaatii luukiirratti barreessitee situ ka'ee ibsa booda (Ok, in this group you will write what the group discusses and report to the class.) Isuma kanaan dura ummattoota kibba Itiyoophiyaa jettanii maal, maal jettanii barattan jechaadha wanta biraa keessa hingaltan itti dabaltanii. (It is what you learnt about south nations and nationalities that you learnt earlier you don't include other topics.) Asiis jedhaa (Here also try it.) Yaada keessan wal jijjiiraa oluma kaasaatii rakkoo hinqabuu Oromiffaanis yoo ta'e Ingiliffaan kan dandeessaniin, (no matter speak loudly and exchange your ideas, no matter if you use Oromo English or any language you can).

In the above extract, the teacher tried to encourage students to make active participation in the group discussion by freeing them to use any language. This implies that the teacher did not take into consideration that it was an EMI class.

\section{Analysis of Data Related to Help from T3}

The analysis of the lesson transcripts of T3 shows that the way he used the local languages does not seem helpful to students as the next extract shows:

T3: Three, very good. Who can tell me? Mention them please. Mee ibsimee eenyudha, hii, hii, eenyudha? (Please explain, what are they, yes, yes what are they?) Let us consider this one as a globe (sketching on the blackboard). This is equator, zero degree; this one is line of Cancer twenty-three and half degree; this is line of Arctic, Arctic Circle sixty-six and half degree; this one is line of Capricorn twenty-three and half degree and also this is sixty-six and half. Ok what is this area who can tell me? Maal jedhama (What do we call it?) The rate? Kun sarara mudhii lafaati kanaafi kana gidduu iddoon jiru addunyaa irratti maal jedhama? (This is the line of equator, what do we call the place found between this and this on the globe?)

As indicated in the quote, the teacher wanted to make the question clear by reverting to students' MT. Explaining the lesson for the second time in English; he repeated the question in Oromo and gave turn in Oromo. However, the student gave answer in the $\mathrm{TL}$ as it should be. Surprisingly, the teacher turned back to Oromo after 
Tamiru Olana and Italo Beriso

repeating the student's response in English without encouraging the student to continue in the TL.

\section{Analysis of Data Related to Help from T4}

T4 always starts lessons in the TL. When he does so, it seems that he intended to use it throughout the period because he speaks in English even when students attempt to switch to Oromo. The next extract makes it clear:

T4: Why, why, why they conflict each other? Do you remember?

S: Zeyilaa [Tireed Ruutii] qabachuudhaaf (To control Zeila Trade Route).

T4: What, what, say it again.

S: Zeyilaa [Tireed Ruutii] qabachuudhaaf (To control Zeila Trade Route).

T4: To control Zeila Trade Route.

In the second turn, the teacher asked the student in English so that he would repeat the answer in English. The way the teacher treated the student's response indicates that he was not encouraging the student's use of the local language. The teacher's last turn depicts this reality as he interestingly translated the student's answer from Oromo into the TL. However, T4 was not observed giving more encouragement the way it is indicated in the example above. Rather he was observed encouraging them to speak in any of the three languages they could saying, "Afaan Oromiffaanis, Amaariffaanis, Ingiliffaanis, sadanuutiinuu nidandeessu." (You can use Oromo, Amharic, English or the 3 of them).

Then, the students continued giving answers in Oromo because they were licensed by the teacher to do so. Besides, the teacher was observed highly dominating the class speaking in the three languages alternately let alone helping the students use the TL.

It is clear that learners use the TL if teachers do so, and this will create an opportunity for students to produce comprehensible output and negotiate meaning by interacting with their teacher and peers (Schweers, 2003). However, what is being practiced in the two schools does not imply that the classrooms are English-medium classrooms, as students are not encouraged by teachers to use the TL and get a chance to practice it. In connection to this, Dalton-Puffer and Smit (2007) report that school subjects are language classes, though the label language classes has been traditionally restricted to classes in which a first language (L1) or second or foreign language (L2) is both the designated subject and the content of interaction. Therefore, the teachers are expected to treat the students in such a way that students can feel that using the TL is mandatory in the subject area classes.

Literature indicates that subject area teachers should take the responsibility for teaching language in Englishmedium classes because English teachers cannot teach all the language skills which learners need for learning subjects (MoE, 2005) though the main objective of is to teach contents of their respective subjects. For example, Ortner (2003) claims that to develop the vocabulary required for academic work and to provide background information that will fire students' imagination and creativity, subject area teachers should play a role which was not observed in the targeted teachers' classes.

\section{Sci. Technol. Arts Res. J., Oct-Dec 2014, 3(4): 179-186}

Concerning lack of awareness, Clegg (2005) uncovers that most African teacher educators have not been orientated to training teachers to teach subjects in L2. He adds that to alleviate the problem, teacher educators should make this issue central to the training of teachers. In line with Clegg's studies, it could be suggested that secondary school teachers need to be aware of their responsibility to consider content obligatory language besides teaching their respective subjects. In relation to this, a study in a Dutch secondary school revealed that teachers focus on the content to be taught to such an extent that they paid little attention to students' language, and their share in the interaction (Snow, 1998). This is, generally, not so because teachers would not want to offer language-sensitive content instruction; rather it may be because they have not been made aware of how to do it. The same thing was observed in the present study. Therefore, the researcher reserves himself from blaming subject area teachers for the failure to help their students. Rather, he believes that lots of awareness creating jobs have to be done around this area.

The other issue the data reveal is that the teaching of language is not only the work of English teachers but it is also the work of content area teachers. Had the teachers implemented what they suggested, it would have gone in line with Stubbs (1992) which reports that all teachers are English teachers and every lesson is an English lesson where English is used as the Mol. However, as the respondents suggested, they could not put it into practice due to a lack of time. In response to the teachers' lack of time, to teach the key terms listed in students' textbooks, one can strongly argue that if students learn the key terms before they start the new units, it would minimise teachers' and students' use of code-switching, which might take more time while shifting from one language to the other.

It is clear that the primary focus of subject area teachers is on teaching content matter but increasing students' awareness of the linguistic features, such as vocabulary, is also found important because paying attention to vocabulary has a more direct influence on learning both the language and the content matter (Marsland, 1997; Kuoppala, 2010).

To improve students' language proficiency, language teachers should work in collaboration with subject area teachers as they (as language teachers) should shoulder more responsibility. Clegg (2005) citing Cummins (2000) argues that English can be used as Mol if English language teachers teach students the language needed to learn subjects. However, referring to the same source, he points out that in Africa or elsewhere, English teachers do not do so except teaching grammar and general purpose English. Clegg (2005) adds that teachers can use EMI if they teach subjects using a specialist language-supportive pedagogy that makes subject concepts acceptable expressing his fear that this is not a habit in Africa.

\section{CONCLUSIONS}

Teachers' view of teachers' help of students to use the TL indicate that they encourage students to use the TL by giving them classroom activities and let them report in the TL. The lesson transcripts data also indicate some trials made by a few teachers. The problem is that these teachers could not even give students time to report to the class, which might give them a chance to try the TL. It is 


\section{Tamiru Olana and Italo Beriso}

true that teaching the key terms that are found in students' textbooks is important and is the duty of History teachers and Geography teachers. However, they could not implement it due to a lack of time. Therefore, it could be concluded that if students learn the key terms before they start the new unit, it will minimise teachers' and students' use of code-switching, which may take more time while shifting from one language to the other. Furthermore, one of the ways teachers can help students is encouraging them to use the TL inside and outside classrooms. However, they were not observed doing what they suggested even in the classrooms.

As students have little opportunity for exposure to the TL outside the classroom and teachers are normally the only expert users of the TL, they should maximise students' use of the TL in class in order to provide them a rich environment to practice the TL. Therefore, it is justifiable to recommend that History teachers and Geography teachers should feel responsible for their students' TL improvement and help them through negotiation instead of changing the classroom atmosphere to education through MT.

The researcher could informally observe that English teachers at the two secondary schools frequently use MT when they teach English. Thus, it could be recommended that many efforts are expected from primary school English teachers to prepare students to use the TL when they join high schools. Furthermore, secondary school English teachers are highly recommended to be role models for other teachers to take part in students' oral English improvement. It is true that English Language Improvement Programme (ELIP) was launched in 2002 (MoE, 2005). However, still, it is justifiable to recommend that sufficient and intensive trainings and workshops that equip subject area teachers with the use of EMI are crucial. Furthermore, a nationwide survey study is important to investigate to what extent teachers help students at the transitional grade (Grade 9) and seek a comprehensive remedy for the inefficiency of teachers in using the TL.

\section{REFERENCES}

Allwright, D. and Bailey, K. (1991). Focus on the language classroom: An introduction to classroom research for language teachers. Cambridge University Press.

Berry, R. (1990). The role of language improvement in inservice teacher training programmes: Killing two birds with one stone. System 18(1): 97-105.

Chaudron, C. (1988). Second language classrooms: Research on teaching and learning. Cambridge: Cambridge University Press.

Clegg, J. (2005). Moving Towards Bilingual Education in Africa. In H. Coleman (Ed.), Language and development: African and beyond, proceedings of the $7^{\text {th }}$ international language and development conference, (pp. 49-64). Addis Ababa, Ethiopia .

Clegg, J. (2002). Towards successful English-medium education in Southern Africa. In D. Marsh, A. Ontero and T. Shikongo (eds.). Enhancing English-medium education in Namibia. Finland: University of Jyväskylä http://www.content- english.org/data/ namibia.pdf

Cohen, L., Manion, L. and Morrison. K. (2000). Research methods in education $\left(5^{\text {th }}\right.$ ed). London: Routledge.
Sci. Technol. Arts Res. J., Oct-Dec 2014, 3(4): 179-186

Crandall, J. (1998). Collaborate and cooperate: Education for integrating language and content instruction. English Teaching Forum 36(2): 3-9.

Cullen, R. (1994). Incorporating a language improvement component in teacher training programmes. ELT Journal 48(2): 162-172.

Dalton-Puffer, C. and Smit, U. (2007). Empirical perspectives on CLIL classroom discourse, 7-23.

Kuoppala, M. (2010). Subject teacher training and teaching in English. Helsinki: University of Helsinki.

Marsland, B. (1997). A language skill approach to teacher training for mainstream plurilingual education. In D. Marsh, B. Marsland and T. Nikula (Eds.), Aspects of implementing plurilingual education: Seminar and field notes, (pp. 36-39) Jyvaskyla: University of Jyvaskyla.

MoE (2005). Language in education in Ethiopian schools: A handbook for teachers and teacher-educators (secondary schools): In collaboration with the graduate school of education, University of Bristol. Addis Ababa: EMPDE.

MoE. (2004). Guidelines for English language enhancement in our schools: A set of practical guidelines to help promote the use of English. Addis Ababa: USAID.

Musumeci, D. (1996). Teacher-learner negotiation in contentbased instruction: Communication at cross-purposes? Applied Linguistics 17(3): 286-325.

Ortner, M. (2003). Language across the curriculum. In M. Hanak-Hammerl and D. Newby (Eds), Second language acquisition: The interface between theory and practice. Summary of findings of a project-based linguistics seminar held at the Department of English Studies of the University of Graz, Austria, (pp. 19-23). Australia: Graz.

Richards, J.C., and Nunan, D. (Eds.) (1990). Second language teacher education. New York: Cambridge University Press.

Richards, J.C., Rodgers, T.S. (2001). Approaches \& methods in language teaching. Cambridge University Press.

Schweers, W. J. (2003). Using L1 in the L2 classroom. English Teaching Forum 41(4): 34-37.

Scott, D., and Usher, R. (2011). Researching education: Data methods and theory in educational inquiry, (second ed.), London: Continuum.

Seime Kebede (1989). An investigation of the listening abilities of Bahir Dar Teachers' College Students (M. A. thesis, Addis Ababa University).

Seliger, H.W. and Shohamy. E. (1989). Second language research methods. Oxford: Oxford University Press.

Snow, M.A. (1998). Trends and issues in content-based instruction. Annual Review of Applied Linguistics 18: 243267.

Stubbs, M. (1992). Language, schools and classrooms (2 $2^{\text {nd }}$ ed.). Bungay: Routledge.

Tadese Terefe (1990). Can a Foreign Language Be a National Medium? In: C.M. Rubagumya (Ed.), Language in education in Africa, (pp. 94-104). Clevedon: Multilingual matters.

Thomas, A. L. (1987). Language teacher competence and language teacher education. ELT Document: London: Modern English publications.

Uys, M., van der, W., van den, A., and Botha, S. (2007). English-medium of instruction: A situation analysis. South African Journal of Education 27(1): 69-82.

Wright, T. and Bolitho, R. (1993). Language awareness: A missing link in language teacher education? ELT Journal 47(4): 292-304. 